\title{
The path to UHC: The Lessons learnt from transitioning from a Community-based to a State- wide health insurance Scheme in Nigeria.
}

Oladimeji Akeem Bolarinwa ( $\sim$ drdeji@yahoo.com )

University of llorin https://orcid.org/0000-0002-7294-8656

Tanimola Makanjuola Akande

University of llorin

Wendy Janssens

Amsterdam Institute for Global Health and Development

Kwasi Boahene

Dutch Health Insurance Fund

Tobias Rinke de Wit

Amsterdam Institute for Global Health and Development

Research article

Keywords: community-based, health insurance, suspension, Kwara

Posted Date: January 6th, 2020

DOI: https://doi.org/10.21203/rs.2.20133/v1

License: (c) (i) This work is licensed under a Creative Commons Attribution 4.0 International License.

Read Full License 


\section{Abstract}

Background Social health insurance has been widely proposed as a key strategy in moving towards universal health coverage. This paper reports on the transition of a community-based health insurance scheme in Kwara State, Nigeria, in 2016 to a state-wide social insurance program. Specifically, it analyses the consequences of the temporary suspension of the community-based insurance scheme during the transition period on healthcare utilization and financial protection.

Methods A mixed methods study was carried out in 2018 using a semi-quantitative cross-sectional survey amongst 600 clients, in-depth interviews with 24 clients and 29 participating public and private healthcare providers.

Results Most former enrollees (95.3\%) kept using Kwara Community Health Insurance Program (KCHIP) facilities, even after the suspension of the program. Over $70 \%$ of respondents reverted to out-of-pocket (OOP) payment for healthcare services and $67 \%$ experienced constraints in payment for healthcare services after suspension of the program. Most common coping mechanisms for healthcare payment was personal savings (63.3\%). Seventeen of 29 facilities recorded a decrease in revenue after suspension of the program. Being male $(\mathrm{OR}=1.61)$, respondents living in rural communities $(\mathrm{OR}=1.77)$, those who use $\mathrm{KCHIP}$ exclusively $(\mathrm{OR}=1.94)$ and acutely ill respondents $(\mathrm{OR}=3.38)$ had increased odds of being constrained with the suspension of the program.

Conclusion After suspension of the KCHIP, many enrollees and health facilities experienced constraints. Enrollees' most important coping mechanisms remained personal savings which has more likelihood of pushing them to catastrophic expenditure.

\section{Introduction}

With only a third of the population in developing countries having access to affordable healthcare, universal health coverage (UHC) has become a major policy prescription in global health. The progress towards UHC involves setting ambitious goals for expanding access to decent health services based on establishing a greater reliance on risk-pooling and prepayment mechanisms to finance health, stimulating investments in healthcare infrastructure and quality, and building human resources and skills for health. The World Health Organization (WHO) estimates that more than half the world's population does not have access to the health services they need, and 100 million people suffer financial catastrophe every year due to out-of-pocket (OOP) expenditures for unexpected healthcare (1). Introduction of a health insurance program is one of the ways to enhance access to healthcare services and to protect individuals from catastrophic health expenditures (2). Financing healthcare through a tax-based system (which is also a form of risk-pooling) is difficult as many Low- and Middle-Income Countries (LMICs) are struggling to mobilize sufficient resources. As a result, OOP expenditures remain high and in combination with poor healthcare services form an important barrier to UHC. How to successfully roll out health insurance on a large scale and ensure sufficient take-up in LMICs is an outstanding question $(3,4)$. 
In Africa, more than half of all healthcare expenses are covered through OOP payments. For example, in Nigeria - the most populous country in Africa, with a population of almost 200 million - there are substantial inequalities in access to healthcare with $72 \%$ of health expenses paid OOP and only about $4 \%$ of the people, mostly in the formal sector, having access to health insurance today (5). Nigeria accounts for $2 \%$ of the world population but contributes to $14 \%$ of maternal deaths and $23 \%$ of malaria cases [2]. To address these burdens, Kwara State, one of the poorest States in Nigeria, with the support of PharmAccess and the Netherlands Health Insurance Fund (HIF), launched a subsidized Community Health Insurance Program in Kwara (KCHIP) in 2007 (6-8). By the year 2015, a total of 347,132 people and 42 public and private healthcare facilities participated in KCHIP (Fig. 1).

The impact of KCHIP has been assessed over time through various studies (Gustafsson-Wright \& Schellekens, 2013; Gustafsson-Wright, Tanović, 2013; Humphreys, 2010), indicating an increase in the use of healthcare (while controlling for additional variables) of up to $90 \%$ among enrolled communities (Gomez et al., 2015; Gustafsson-Wright, Tanović, 2013), markedly improved cost-effectiveness, as well as substantial benefits in terms of improved health outcomes especially in relation to chronic diseases like hypertension (10), and maternal and child care (11). Similarly, OOP expenditures significantly decreased by $50 \%$ among enrollees, thus securing more financial protection in the medium run $(7,9)$. It was also found to increase awareness about health status $(9,12)$. Additionally, it was demonstrated that the program can deliver a basic quality healthcare coverage at US $\$ 28$ per person per year, compared to the WHO benchmark of US $\$ 60$ and Nigeria's total health expenditure per capita of US $\$ 115$ (8).

An important feature of KCHIP was that there would be incremental financial commitment and ownership of the program by the Kwara State Government over time. The program was aimed at synergizing with the Nigeria National Health Insurance Program (NHIS) with a view to attaining UHC for the State (13). In January 2015 (Fig. 1), the program partners signed an agreement to transition KCHIP to the Kwara State Health Insurance Program (KSHIP). Pending this arrangement, KCHIP enrolment was temporarily suspended while designing a new insurance product and premium to be introduced and deployed on a state-wide level. Whereas in January 2016, KCHIP was active in 11 out of the 16 Local Government Areas (LGAs) in Kwara State and recorded a total enrolment of 139,714 clients, these clients were not renewed over the course of 2016. This resulted in a gradual drop-out over the year with no clients insured by January 2017 (Fig. 1). Therefore, a unique 'reverse insurance intervention' situation emerged, which is evaluated in this study.

This paper describes the consequences of suspension of KCHIP in Kwara state, Nigeria, in wait of a statewide health insurance, and analyses the effects on healthcare quality, utilization and ability to pay for healthcare among former enrollees, as well as the consequences for formerly participating KCHIP health facilities.

\section{Methodology}

Study design and study population 
In August 2018, about 2 years after suspension of KCHIP (Fig. 1), a mixed method study was carried out among KCHIP former enrollees and healthcare providers in Kwara State, Nigeria. Using multi-stage random sampling, we recruited 600 previously insured respondents for a semi-quantitative crosssectional survey to obtain data on socio-demographics, healthcare utilization, enrolment status, healthcare constraints and coping strategies since suspension. Only adults (18 years and above) were included in the study, of whom a purposively selected 400 had accessed care in a KCHIP healthcare facility in the preceding 12 months while 200 being not insured in the past 12 months. Of those participants who have accessed healthcare, half (200) were selected who had in addition to other health conditions been seeking chronic care, maternal care and care for acute conditions.

In addition, in-depth interviews (IDIs) were performed among 24 purposively selected former enrollees and among 29 health facilities' managers of participating KCHIP facilities (19 public, 10 private). IDIs explored the effects of the program suspension on both healthcare utilization by former enrollees and their coping mechanisms, and health facilities' service provision. Inclusion criteria for IDIs were participant age (18 years and above) and at least once utilization of pertinent healthcare in the past 12 months. Health facilities' clinical records were reviewed as part of the observation checklist within the qualitative data tool used.

Sampling and Data collection

Quantitative study: We recruited a total of 600 respondents whose health insurance policy had expired at least 4 months prior to the end of December 2016. Multi-stage sampling was used, selecting 5 Local Government Areas (LGAs): 2 from Kwara South, 2 from Kwara North and 1 from Kwara Central senatorial zones. Respondents were selected randomly with the KCHIP enrollment database serving as sampling frame after LGAs were allocated proportionate to constituent population sizes (with total enrollment in the 5 LGAs in January 2016 being 73,438). An additional 30\% was added from the sample frame for each LGA to cater for non-response and untraceable respondents. The selected respondents were traced in the community (with the help of community mobilizers) and interviewed by trained interviewers. The questionnaire captured data on respondents' socio-economic characteristics, morbidity patterns, healthcare access and utilization in the preceding 12 months.

Qualitative study

We conducted two rounds of IDIs among former enrollees and facilities' managers. The enrollees' interviews were conducted among 24 purposively selected adults across 9 selected LGAs cutting across the 3 zones of Kwara State. The selection of former enrollees into the IDIs was carried out in and around the health facilities using a pretested interview guide. The facility managers' interviews were conducted in KCHIP facilities among the officers-in-charge (or the Medical Director). This comprised all 29 Enhanced Community Based Care (ECBC) health facilities (19 public, 10 private) spread across 9 LGAs; 13 health posts providing remote care services were excluded from the study because they were already linked to records of the 29 ECBCs.

\section{Data Analysis}


The quantitative data entry platform was designed using Open Data Kit (ODK), while the data was entered using Kobo Toolbox (14)and later exported to Statistical Package for Social Science (SPSS) for analysis. Simple logistic regression was used to explore the predictive factors of the constraints in the ability to pay for healthcare services after the program suspension. The level of significance was set at a p-value of $<0.05$ complemented with $95 \%$ confidence interval $(\mathrm{Cl})$. Qualitative interviews were transcribed and thematic analysis was carried out. The results of the former enrollees' IDIs are reported together in context of quantitative data.

\section{Results}

Socio-demography of the respondents

The respondents had a median age of 43 years and $74.5 \%$ were women (Table 1 ). Close to half of the respondents did not have formal education (42.5\%); $77.2 \%$ were married, $17.2 \%$ widows. About threequarters of the respondents (73.8\%) lived in semi-urban areas (Table 1$)$. The respondents were majorly Yoruba (64.5\%) and Nupe (32.2\%) ethnic groups, while Islam (83.2\%) was the predominant religion amongst them. The respondents were equally spread over the wealth quintiles, with wealth calculated as annual per capita consumption of food and non-food items. 
Table 1

Socio-demographic and Socio-economic Characteristics of the Respondents

\begin{tabular}{|c|c|c|}
\hline Socio-demography & $\mathrm{n}(\%)$ & Median (IQR) \\
\hline \multicolumn{3}{|l|}{ Gender } \\
\hline Male & $153(25.5)$ & \\
\hline Female & $447(74.5)$ & \\
\hline $\begin{array}{l}\text { Age group (years) } \\
\leq 20\end{array}$ & $21(3.5)$ & \\
\hline $21-30$ & $141(23.5)$ & \\
\hline $31-40$ & $125(20.8)$ & \\
\hline $41-50$ & $91(15.2)$ & \\
\hline $51-60$ & $84(14.0)$ & \\
\hline $61-70$ & $76(12.7)$ & \\
\hline$\geq 71$ & $62(10.3)$ & \\
\hline Median age (years) & & $43(30)$ \\
\hline \multicolumn{3}{|l|}{ Highest level of Education } \\
\hline No formal education & $255(42.5)$ & \\
\hline Less than primary education & $20(3.3)$ & \\
\hline Primary education & $77(12.8)$ & \\
\hline JSS education & $22(3.7)$ & \\
\hline SSS education & $79(13.2)$ & \\
\hline Post-secondary & $121(20.2)$ & \\
\hline Quranic education & $26(4.3)$ & \\
\hline \multicolumn{3}{|l|}{ Marital status } \\
\hline Married & $463(77.2)$ & \\
\hline Single & $33(5.5)$ & \\
\hline Divorced & $1(0.1)$ & \\
\hline Widowed & $103(17.2)$ & \\
\hline Residence & & \\
\hline
\end{tabular}




\begin{tabular}{|c|c|c|}
\hline Socio-demography & $\mathrm{n}(\%)$ & Median (IQR) \\
\hline Semi-Urban & $443(73.8)$ & \\
\hline Rural & $157(26.2)$ & \\
\hline \multicolumn{3}{|l|}{ Ethnicity } \\
\hline Yoruba & $387(64.5)$ & \\
\hline Nupe & $193(32.2)$ & \\
\hline Hausa & $16(2.6)$ & \\
\hline Others & $4(0.7)$ & \\
\hline \multicolumn{3}{|l|}{ Religion } \\
\hline Islam & 499 (83.2) & \\
\hline Christianity & $101(16.8)$ & \\
\hline \multicolumn{3}{|l|}{ Wealth Quintile } \\
\hline 1 (poorest) & $126(21.0)$ & \\
\hline 2 & $119(19.8)$ & \\
\hline 3 & $131(21.8)$ & \\
\hline 4 & $108(18.0)$ & \\
\hline 5 (richest) & $116(19.4)$ & \\
\hline
\end{tabular}

Consequences of (re)enrolment suspension on households

The survey shows that the far majority of former enrollees (95.3\%) still kept using a KCHIP facility, even after the suspension of the program (Table 2). This observation was confirmed by IDI statements like: "the hospital has very friendly staff" and "I won't go to another facility because I have confidence in the doctor here". After suspension of KCHIP, $74.0 \%$ of respondents mentioned they reverted to OOP payment for healthcare services, mostly remaining at the same private KCHIP facilities. The others who were not able to pay OOP often appeared fully $(4.2 \%)$ or partially $(21.8 \%)$ exempted by the private providers from paying. The IDIs revealed that for many patients this was due to friendship and cordial relationships built over the years with health workers at the KCHIP facilities. For other respondents the KCHIP facilities allowed to pay in tranches for reasons of empathy and familiarity. 
Table 2

Preferences and constraints in ability to pay for and accessibility to healthcare after $\mathrm{KCHIP}$ suspension

\begin{tabular}{|c|c|}
\hline Preferences/constraints/Coping mechanism & $\mathrm{n}(\%)$ \\
\hline \multicolumn{2}{|l|}{ Prefer KCHIP facility } \\
\hline Yes & $572(95.3)$ \\
\hline No & $28(4.7)$ \\
\hline \multicolumn{2}{|l|}{ Current payment options for health services at KCHIP facilities } \\
\hline Pay for everything & $444(74.0)$ \\
\hline Pay some, but at reduced costs & $131(21.8)$ \\
\hline Not pay for anything & $25(4.2)$ \\
\hline \multicolumn{2}{|l|}{ Constrained ability to pay for healthcare services } \\
\hline No & $198(33.0)$ \\
\hline Yes & $402(67.0)$ \\
\hline \multicolumn{2}{|l|}{ Main reasons for the constraints $(n=402)$} \\
\hline Due to the suspension & $184(30.8)$ \\
\hline Due to the economic situation of the country & $68(11.2)$ \\
\hline Due to both the suspension and the economic situation of the country & $150(25.0)$ \\
\hline \multicolumn{2}{|l|}{ Coping mechanism $(n=600)^{\wedge}$} \\
\hline From personal savings & $380(63.3)$ \\
\hline Donation from friends and families & $208(34.7)$ \\
\hline Borrowing (friends / families) & $71(11.8)$ \\
\hline Borrowing from local money lenders & $4(0.7)$ \\
\hline Sell properties & $3(0.5)$ \\
\hline Loan (co-operatives / Banks) & $4(0.7)$ \\
\hline Support from trade unions & $5(0.8)$ \\
\hline Support from religious groups (church or mosque) & $4(0.7)$ \\
\hline Have not been ill since program stopped & $29(4.8)$ \\
\hline
\end{tabular}




\begin{tabular}{|ll|}
\hline Preferences/constraints/Coping mechanism & $\mathbf{n}(\%)$ \\
\hline Others identified coping & $66(11.0)$ \\
\hline Other identified coping $(\mathrm{n}=66)$ & \\
\hline Petty trading & $17(25.8)$ \\
\hline Husband & $13(19.7)$ \\
\hline Children & $3(4.5)$ \\
\hline Others & $33(50.0)$ \\
\hline Accessibility to healthcare since suspension of KCHIP & \\
\hline Much worse & $78(13.0)$ \\
\hline Worse & $296(49.3)$ \\
\hline Same & $172(28.7)$ \\
\hline Better & $38(6.3)$ \\
\hline Much better & $10(1.7)$ \\
\hline Don't know & $6(1.0)$ \\
\hline Membership of financial/social groups $(\mathrm{n}=600)^{\wedge}$ & \\
\hline Contribution (Ajo) & $284(47.3)$ \\
\hline Religious group & $171(28.5)$ \\
\hline Community group & $112(18.7)$ \\
\hline Cooperative & $105(17.5)$ \\
\hline Trade union & $49(8.2)$ \\
\hline Social club & $152(25.3)$ \\
\hline None of the above & \\
\hline ^ Multiple responses & $32.3)$ \\
\hline
\end{tabular}

It was observed that after suspension, $67.0 \%$ of respondents experienced constraints in the ability to pay for healthcare services; $30.8 \%$ reported it was due to the suspension, $11.2 \%$ to the economic situation of the country while $25.0 \%$ said it was due to both (Table 2). The IDIs corroborated these quantitative findings, showing that almost all respondents reported a change in their ability to pay for services. Many respondents summed it up as "my ability to pay has been hampered seriously by lack of funds, even my children are struggling to get by and some don't have jobs". A minority (33.0\%) of respondents reported little or no change in their ability to pay for healthcare services. 
Most common coping mechanisms for payment according to the survey were personal savings (63.3\%), donations from friends and families (34.7\%) and borrowing (11.8\%). Other coping mechanisms included proceeds from petty trading (25.8\%), money given by husbands $(19.7 \%)$ and money received from children (4.5\%). According to the IDIs, the most commonly identified coping mechanism was the use of family savings to offset health facility bills while others had to borrow from friends and family members, including seeking assistance from children in paying hospital bills. The quantitative data showed that specific social groups offered health benefits to members such as donations during episodes of illness and loan facilities to offset medical bills. These were (Table 2): Ajo - a local thrift (47.3\%), religious groups (28.5\%), community groups (18.7\%) and cooperative groups $(17.5 \%)$.

Factors associated with constrained ability to pay for healthcare after the program suspension

Table 3 displays different factors associated with the (in)ability to pay for healthcare after insurance suspension. Constraints were experienced more often by male respondents $(74.5 \%, p=0.022)$, living in rural locations $(75.8 \%, p=0.006)$, as compared to females and semi-urban residents, and by those having an acute illness/injury in the preceding 12 months $(74.3 \%, p<0.001)$. In addition, ethnic groups other than Yoruba (Nupe $89.6 \%$ and Hausa $87.5 \%)$ in the study $(p<0.001)$ and those respondents that patronized KCHIP facilities exclusively while in the program $(68.1 \%, p<0.001)$ were significantly more likely to be constrained to pay for healthcare services after the program suspension. Wealth was also significantly associated with ability to pay, with the poorest quintiles substantially more likely to experience constraints. Many of the people who were constrained by the suspension of the scheme perceived the government default in counterpart funding as well as the withdrawal of the original funder from further finance as responsible for the suspension. 
Table 3

Factors associated with constraints in ability to pay for healthcare services after re-enrollment suspension

\begin{tabular}{|c|c|c|c|c|c|}
\hline \multirow[t]{2}{*}{ Factors } & \multicolumn{3}{|c|}{$\begin{array}{l}\text { Constrained Ability to } \\
\text { Pay }\end{array}$} & \multirow[t]{2}{*}{$x^{2}$} & \multirow[t]{2}{*}{$\begin{array}{l}\mathrm{p}- \\
\text { value }\end{array}$} \\
\hline & $\begin{array}{l}\text { Yes } \\
\mathrm{n}(\%)\end{array}$ & $\begin{array}{l}\text { No } \\
\mathrm{n}(\%)\end{array}$ & & & \\
\hline Gender & & & & 5.238 & $0.022 *$ \\
\hline Male & \multicolumn{2}{|c|}{$114(74.5)$} & \multicolumn{2}{|c|}{39 (25.5) } & \\
\hline Female & \multicolumn{2}{|c|}{$288(64.4)$} & \multicolumn{2}{|c|}{$159(35.6)$} & \\
\hline Residence & & & & 7.441 & 0.006 * \\
\hline Semi-Urban & \multicolumn{2}{|c|}{$283(63.9)$} & \multicolumn{2}{|c|}{$160(36.1)$} & \\
\hline Rural & \multicolumn{2}{|c|}{$119(75.8)$} & \multicolumn{2}{|c|}{$38(24.2)$} & \\
\hline Ethnic group & & & & 74.025 & $\begin{array}{l}<.001 * \\
\end{array}$ \\
\hline Yoruba & \multicolumn{2}{|c|}{$212(54.8)$} & \multicolumn{2}{|c|}{$175(45.2)$} & \\
\hline Nupe & \multicolumn{2}{|c|}{173 (89.6) } & \multicolumn{2}{|c|}{$20(10.4)$} & \\
\hline Hausa & \multicolumn{2}{|c|}{$14(87.5)$} & \multicolumn{2}{|c|}{$2(12.5)$} & \\
\hline Others & \multicolumn{2}{|c|}{$3(75.0)$} & \multicolumn{2}{|c|}{$1(25.0)$} & \\
\hline Wealth Quintile & & & & 16.739 & $0.002^{*}$ \\
\hline 1 & \multicolumn{2}{|c|}{$98(77.8)$} & \multicolumn{2}{|c|}{$28(22.2)$} & \\
\hline 2 & \multicolumn{2}{|c|}{$87(73.1)$} & \multicolumn{2}{|c|}{$32(26.9)$} & \\
\hline 3 & \multicolumn{2}{|c|}{$86(65.6)$} & \multicolumn{2}{|c|}{$45(34.4)$} & \\
\hline 4 & \multicolumn{2}{|c|}{66 (61.1) } & \multicolumn{2}{|c|}{$42(38.9)$} & \\
\hline 5 & \multicolumn{2}{|c|}{$65(56.0)$} & \multicolumn{2}{|c|}{$51(44.0)$} & \\
\hline Perceived reasons for the KSCHIP suspension & & & & 19.949 & $0.001 *$ \\
\hline Government failure to provide funds & \multicolumn{2}{|c|}{$142(62.6)$} & \multicolumn{2}{|c|}{$85(37.4)$} & \\
\hline Hygeia no longer fund the program & \multicolumn{2}{|c|}{$99(83.9)$} & \multicolumn{2}{|c|}{$19(16.1)$} & \\
\hline Stoppage of foreign fund & $3(42$ & & $4(57$. & & \\
\hline
\end{tabular}




\begin{tabular}{|c|c|c|c|c|c|c|}
\hline \multirow[t]{2}{*}{ Factors } & \multicolumn{3}{|c|}{$\begin{array}{l}\text { Constrained Ability to } \\
\text { Pay }\end{array}$} & \multirow[t]{2}{*}{$x^{2}$} & & \multirow[t]{2}{*}{$\begin{array}{l}\mathrm{p} \text { - } \\
\text { value }\end{array}$} \\
\hline & $\begin{array}{l}\text { Yes } \\
\mathrm{n}(\%)\end{array}$ & $\begin{array}{l}\text { No } \\
n(\%)\end{array}$ & & & & \\
\hline No reason given & \multicolumn{2}{|c|}{$139(67.5)$} & \multicolumn{3}{|c|}{67 (32.5) } & \\
\hline Others & \multicolumn{2}{|c|}{9 (56.2) } & \multicolumn{3}{|c|}{$7(43.8)$} & \\
\hline $\begin{array}{l}\text { Utilization of non-KSCHIP facility while in the } \\
\text { program }\end{array}$ & & & & & 4.365 & $0.037 *$ \\
\hline Yes & \multicolumn{2}{|c|}{$22(52.4)$} & \multicolumn{3}{|c|}{$20(47.6)$} & \\
\hline No & \multicolumn{2}{|c|}{$380(68.1)$} & \multicolumn{3}{|c|}{178 (31.9) } & \\
\hline $\begin{array}{l}\text { Suffering for any acute illness or injury in last } 12 \\
\text { months }\end{array}$ & & & & & 41.434 & $<.001 *$ \\
\hline Yes & \multicolumn{2}{|c|}{$33(74.3)$} & \multicolumn{3}{|c|}{$114(25.7)$} & \\
\hline No & \multicolumn{2}{|c|}{$72(46.2)$} & \multicolumn{3}{|c|}{$84(53.8)$} & \\
\hline
\end{tabular}

Per Table 4, odds ratios for payment constraints were: being male ( $\mathrm{OR}=1.61,95 \% \mathrm{Cl}=1.069 ; 2.436)$, and living in rural communities $(\mathrm{OR}=1.77,95 \% \mathrm{Cl}=1.171 ; 2.677)$. The former enrollees of Yoruba ethnicity $(\mathrm{OR}=0.15,95 \% \mathrm{Cl}=0.091 ; 0.236)$ had less difficulties paying for healthcare services after the program suspension compared to people from other ethnicities. Those respondents who depended solely on KCHIP health facilities had increased odds $(\mathrm{OR}=1.94,95 \% \mathrm{Cl}=1.032 ; 3.648)$ of paying constraints (Table 4). The respondents with acute illness or injury in the preceding 12 months also had increased odds $(\mathrm{OR}=3.38,95 \% \mathrm{Cl}=2.309 ; 4.939)$. 
Table 4

Predictors of Constrained ability to pay for healthcare services after the suspension of the program

\begin{tabular}{|c|c|c|c|c|c|}
\hline Factor & $\beta$ & p-value & $\begin{array}{l}\text { Crude } \\
\text { OR }\end{array}$ & $\begin{array}{l}95 \% \\
\text { Lower }\end{array}$ & $\begin{array}{l}\text { Cl } \\
\text { Upper }\end{array}$ \\
\hline Male Gender & 0.479 & $0.023^{\star}$ & 1.614 & 1.069 & 2.436 \\
\hline Age & 0.004 & 0.454 & 1.004 & 0.994 & 1.013 \\
\hline Rural inhabitants & 0.571 & $0.007 *$ & 1.771 & 1.171 & 2.677 \\
\hline Yoruba Ethnic group & -1.920 & $<.001 *$ & 0.147 & 0.091 & 0.236 \\
\hline Higher Wealth Quintiles & -0.255 & $<0.001^{*}$ & 0.775 & 0.685 & 0.877 \\
\hline $\begin{array}{l}\text { Utilize only KSCHIP facilities while in the } \\
\text { program }\end{array}$ & 0.663 & $0.039 *$ & 1.941 & 1.032 & 3.648 \\
\hline Enrollees with acute illness or injury & 1.217 & $\begin{array}{l}<.001 * \\
0.00\end{array}$ & 3.377 & 2.309 & 4.939 \\
\hline Enrollees with chronic illness & 0.260 & 0.154 & 1.298 & 0.907 & 1.856 \\
\hline Membership of financial group & 0.379 & 0.068 & 1.461 & 0.972 & 2.195 \\
\hline
\end{tabular}

Consequences of the suspension of (re)enrolment on the program health facilities: Health providers' interview report and hospital records review

After suspension, 24 of 29 health facilities claimed the quality and quantity of services provided remained the same while 5 confirmed reduction in service provision. In the past, more than two-thirds of the health facilities claimed they experienced increased patronage and service utilization due to KCHIP. However, with the suspension of the program, review of records revealed that all facilities experienced a significant reduction in out-patient loads as there was gradual decline in healthcare utilization in the clinics record (Fig. 2). No appreciable effect was seen on in-patient visits (Fig. 3). Out of those that reported reduction in service provision, a facility manager said; "At present, just about $5 \%$ of those previously registered on the program are still coming to the health facility for treatment" Another commented: "We saw just 2 patients today, compared to the time when the program was in place whereby we will not have the time to even attend to you to have this interview."

Seventeen of 29 facilities recorded a decrease in revenue after suspension of the program, while 9 recorded an increase in their revenue, despite a reduction in patient load; the facilities in this category were all public health facilities. They attributed this increase to the removal of restrictions on billing patients directly during the enrollment period. A facility manager said, "Our revenue has increased because patients now have to pay out of pocket unlike when the program was running and drugs and 
tests were done freely." Another said: "Our revenue has increased because people coming to the hospital now pay for services." Similarly, 23 out of 29 facilities experienced a reduction in staff after suspension of KCHIP. For 26 out of 29 facilities staff experienced a reduction in salary. The loss of incentives and salary cut reduced staff motivation and productivity. One of the facility managers said: "With the suspension of the program, the revenue generated could not cater for the salaries of all the staff so 39 members of staff were laid off and those that remained (31) had a $40 \%$ salary cut. The hard lesson we learnt was not to depend on the program". Another said, "The salary cut as well as loss of incentives has resulted in a low productivity of staff members who claim not to be motivated anymore". In addition, 21 out of 29 facilities experienced a decrease in drug purchase, with 7 out of 29 seeing an increase after suspension of the program.

\section{Discussion}

This study assessed the consequences of the suspension of a community-based health insurance program in Kwara State, Nigeria. This suspension was due to the preparations required for a major Government policy change towards the commencement of a state-wide health insurance program. For this reason a unique situation emerged, which allowed for a 'reverse intervention' evaluation of a community-based health insurance. This was performed by a mixed method study on both the former enrollees and participating healthcare providers.

First of all, it was observed that despite the suspension of KCHIP, the large majority of former enrollees still preferred to use the KCHIP health facilities. This was mostly due to extended positive experiences and relationships previously established with the KCHIP health facilities, perceived quality of care and geographic proximity. The quality upgrades previously performed with the providers as part of KCHIP most likely contributed to this observation. In addition to facility infrastructure upgrade, other quality improvement interventions included implementation of treatment guidelines and protocols for waste management and hospital infection control, training of staff in guideline-based care and adequate medical file keeping, hospital renovation, upgrading of laboratory equipment and training of laboratory staff in basic laboratory testing and assurance of continuous essential drug supplies $(10,11)$. All in all, there are basically few alternative options of similar medical quality available for Kwara patients. This corroborates the propensity of community-based health insurance, when combined with quality improvement of medical services, to remove barriers to UHC (4).

This study also demonstrated that three-quarters of the former KCHIP enrollees reverted to OOP payment for their healthcare services. Remarkably, and apparently as a result of the established relationships with KCHIP facilities, the remaining one-quarter of enrollees were treated for free or were allowed to make partial or tranche-wise payments, even with private healthcare providers. This could be an indicator of build-up of social benefits from the KCHIP, though at a certain cost to the healthcare providers. The high rate of reversal to OOP obviously endangered the original insurance aspirations and benefits of KCHIP $(6,8,10)$ and it also represents a potential threat, which can plunge enrollees into catastrophic health expenditure $(8,15)$. 
We show that of the two-thirds of former enrollees who experienced constraints to pay for healthcare services, the KCHIP suspension as well as the general economic recession in Nigeria were mentioned as most important perceived causes. Economic recession has been reported elsewhere to cause reduction in individual expenditure and health insurance consumption power (16)[14]. we found that the KCHIP suspension had additional and immediate consequences for former enrollees, leading to the adoption of financial coping mechanisms like personal savings, donations and borrowing. Respondents also reported receiving support from financial or social groups in the form of "ajo" contributions, religious groups, community groups and cooperative groups. These were beneficial to individuals who required funds for sickness. Such financial/social groups could be effective coping strategies in terms of improved household income (17).

The male enrollees living in the rural communities reported more difficulties paying for healthcare services after the program suspension. This is in line with a study on catastrophic health expenditure in Nigeria, which concluded that female-headed households were less likely to incur catastrophic expenses compared to male-headed households (18). This may reflect a lower access to healthcare services and higher foregone formal care among women compared to men $(19,20)$. The Yoruba ethnic group appeared less constrained to pay for healthcare services after the suspension.

Living in rural communities of Nigeria is associated with poverty, poor infrastructure and lack of geographical and financial access to healthcare services (21). Our findings on the wealth quintiles that indicated a significant socio-economic gradient in access to healthcare after suspension looks similar to the inference by another local study (22), which concluded that the richer quintiles indeed experienced less catastrophic health expenditure. Enrollees who experienced an acute illness or injury in the preceding 12 months prior to the suspension of enrollment had reduced odds of being able to cope with the suspension of the program. A previous study in Kwara State on spending for non-communicable chronic disease (NCCD) reported health expenditures relative to annual consumption of the poorest quintile exceeding those of the highest quintile 2.2-fold, and the poorest quintile exhibiting a higher rate of catastrophic health spending (10.8\% among NCCD-affected households) than the three upper quintiles (4.2-6.7\%) (19). Several Nigerian studies (22) also reported increased risk of incurring catastrophic health expenditures for household members with non-chronic illnesses. This finding implied that both enrollees with acute illnesses and chronic disease are bound to suffer the consequences of the program suspension.

While there were no serious consequences with respect to the range of service provision, a significant reduction in patient load in (almost) all of the KCHIP facilities was observed. However, there were slight spikes on patient load around the wet months of the year, which corroborated seasonal patterns of seeking healthcare (mostly related to malaria season and harvest time). All health facilities' revenues dropped considerably as enrollees exited the program. Private health facilities experienced higher drops in revenue after KCHIP suspension. Public facilities still received stipends from the government to run their services, which cushioned the effects. Some public health facilities even reported an increase in revenue generation because of the removal of (national) insurance program restrictions on the direct billing of the 
patients and possibly also due to some shift of private patients towards the public sector. Private health facilities disproportionately suffered a reduction in staff strength, motivation and productivity. This resulted in downsizing of staff in many of these facilities. In addition, we observed a downward trend in drug purchase among the private health facilities, which remained unchanged in public facilities that kept benefiting from supply of essential drugs from the Ministry of Health. Finally, the suspension of KCHIP was reflected by clear downward out-patient department visits, but in-patient visits remained the same. This is probably due to the severity of medical reasons for an in-patient visit, that cannot be ignored or postponed. Consequences for OOP expenditures are corresponding.

In the literature, suspending an impactful health insurance program is an uncommon policy decision. This is probably due to high political sensitivity and the legislative bureaucracy that such action will cause. In January 2016, the Qatari government suspended a State-financed mandatory national health insurance program due to inability to sustain the exclusive funding of the program because of a fall in global oil prices (23). Experts expected in the short term a larger private sector involvement in the Qatari healthcare coverage, while in the long term an uncertainty regarding payment of Qataris' medical bills and UHC. The suspension of the Qatari health insurance program adversely affected hospitals, health centres and patients, which caused negative outcry among the population (23). Similar observations are made in Kwara with respect to deteriorating access to healthcare, which happened much rapidly due to the weaker healthcare infrastructure and poverty status of the population. Shifting from fragmented smaller-scale community-based health insurance schemes to a larger State-owned insurance program is a precarious process. Lessons can be learnt from elsewhere in Africa, like the development of the National Health Insurance Scheme (NHIS) in Ghana (24), the political path to impactful community health insurance in Rwanda (25) and the transition of the improved Community Health Fund (iCHF) into a National iCHF in Tanzania (26). Common recommendation is the introduction of a transition phase with clearly defined services before the new larger-scale insurance package is introduced, providers are assigned and financial coverage is arranged for instance through tax systems, like VAT such as in Ghana (24).

This paper demonstrates that temporary suspension of health insurance in the absence of transitional measures has consequences for clients and healthcare providers, but it also provides opportunities to learn lessons that help re-engineering schemes to improve effectiveness and efficiency. For example, it was learnt that transition periods can benefit from leveraging on previously built social capital, including the network of relations between former enrollees and healthcare providers, as well as the support from particular social groups (religious, community and cooperatives). It was also learnt that refurbishment of health facilities and quality improvement of services during the previous phase of community-based health insurance was appreciated also during suspension of the KCHIP, with people continuing to visit KCHIP healthcare facilities. At the policy level, Kwara State worked to adopt a law that makes health insurance mandatory for all inhabitants and requires that the State government commits one percent of its revenues to finance health insurance. In addition, during the transition phase Kwara State started the process of setting up a dedicated State Health Insurance Fund that pools financial contributions from 
diverse sources, including the State government, the Federal Government of Nigeria (particularly Ministry of Health and National Health Insurance Program) and individual enrollees.

\section{Conclusion}

After suspension of the KCHIP health insurance program in Kwara State, Nigeria, former enrollees still preferred using the KCHIP health facilities and they reverted almost ubiquitously to OOP payments. At the same time, out-patient healthcare consumption decreased substantially, with a large proportion of former enrollees not being able to afford healthcare services. Belonging to some form of financial/social group proved beneficial in the short term as a coping mechanism. Social capital built through KCHIP between former enrollees and clinics helped alleviate part of the financial burden for the former enrollees, but not for the facilities. Enrollees with the highest probability of suffering adverse consequences of the program suspension were households in the lower social quintiles, living in rural communities and those reporting recent acute illness. Private health facilities suffered more consequences of the program suspension than public facilities in terms of reduced financial inflow sequel to change in the revenue and resources. These observations point to the need of designing effective transition processes from community-based health insurance to State insurance in other Nigerian states.

\section{Declarations}

Ethics approval and consent to participate: Written permissions were obtained from the ethics committee of the Kwara State Ministry of Health, Ilorin, Nigeria. Informed consent was obtained from the participants Confidentiality of the participants' and health facilities' information were maintained.

Consent for publication: Not applicable to this research

Availability of data and materials: Because of the sensitivity of the data sets to the Kwara state Government and the health facilities in the KCHIP, the research data set were securely stored in both hard and soft copies in research office in Ilorin, Nigeria.

Competing interests: Though PharmAccess Foundation funded this study and one of the authors work at the company, the study was not influence by his participation in the design, data collection and manuscript writing. We therefore declare no financial or non-financial conflict or competing of interest 
Funding: PharmAccess Foundation, Netherlands for providing funding for this study

Authors' contributions: BOA, participated in the design of the research tool and data collection. He analyzed and made fisrt draft of the manuscript. ATM, participated in the design of the research tool, data collection and review of the manuscript. JW, participated in the design of the research tool and reviewed the manuscript BK, participated in the design of the research tool and reviewed the manuscript. TRdW, participated in the design of the research tool and reviewed the manuscript.

Acknowledgements: We wish to acknowledge the support of the Kwara State Government to the research team

\section{References}

1. WHO, The World Bank. Tracking Universal Health Coverage: 2017 Global Monitoring Report [Internet]. World Health Organisation. 2017. 88 p. Available from:

https://www.who.int/publications/almaata_declaration_en.pdf\%0Ahttp://www.who.int/genderequity-rights/knowledge/anchoringuhc.pdf\%0Ahttp://apps.who.int/iris/bitstream/handle/10665/259817/9789241513555eng.pdf;jsessionid=C29E21005A5692511BE2B70BD2D3C941?se

2. Kapologwe NA, Kagaruki GB, Kalolo A, Ally M, Shao A, Meshack M, et al. Barriers and facilitators to enrollment and re-enrollment into the community health funds/Tiba Kwa Kadi (CHF/TIKA) in Tanzania: a cross-sectional inquiry on the effects of socio-demographic factors and social marketing strategies. BMC Health Serv Res. 2017;17(1):1-9.

3. Adebayo EF, Ataguba JE, Uthman OA, Okwundu Cl, Lamont KT, Wiysonge CS. Factors that affect the uptake of community-based health insurance in low-income and middle-income countries: A systematic protocol. BMJ Open. 2014;4(2):1-5.

4. WHO. The World Health Report HEALTH SYSTEMS FINANCING [Internet]. 2010 [cited 2017 Jun 5]. Available from: http://apps.who.int/iris/bitstream/10665/44371/1/9789241564021_eng.pdf

5. Adewole DA, Bolarinwa OA, Dairo MD. National Health Insurance Scheme and Universal Health Coverage among Formal Sector Employees in Ilorin , Nigeria: Has Any Progress Been Made? 2016;18(4):1-10.

6. Humphreys G. Nigerian farmers rejoice in pilot insurance plan. Bull World Health Organ. 2010;88(5):329-30. 
7. Gustafsson-Wright Emily, Tanović Zlata AD. A Short -Term Impact Evaluation of the Health Insurace Fund Program in Cetral Kwara State, Nigeria. Aiid. 2013;

8. Gustafsson-Wright E, Schellekens O. Achieving Universal Health Coverage in Nigeria One State At a Time. A Public-Private Partnership Community-Based health insurance Model. Brooke Shear Work Pap Ser. 2013;(2):1-28.

9. Gomez GB, Foster N, Brals D, Nelissen HE, Bolarinwa OA, Hendriks ME, et al. Improving maternal care through a state-wide health insurance program: A cost and cost-effectiveness study in rural Nigeria. PLoS One [Internet]. 2015;10(9):1-17. Available from:

http://dx.doi.org/10.1371/journal.pone.0139048

10. Hendriks ME, Wit FWNM, Akande TM, Kramer B, Osagbemi GK, Tanovic Z, et al. Effect of health insurance and facility quality improvement on blood pressure in adults with hypertension in nigeria a population-based study. JAMA Intern Med. 2014;174(4):555-63.

11. Brals D, Aderibigbe SA, Wit FW, Van Ophem JCM, Van Der List M, Osagbemi GK, et al. The effect of health insurance and health facility-upgrades on hospital deliveries in rural Nigeria: A controlled interrupted time-series study. Health Policy Plan. 2017;32(7):990-1001.

12. Health Insurance Fund. The Impact of Access to Quality Healthcare in Africa. 2015;(February). Available from: https://www.pharmaccess.org/update/the-impact-of-access-to-quality-healthcare-inafrica-research-findings-on-hif-supported-programs/

13. Government of Kwara state. A LAW TO ESTABLISH THE KWARA STATE HEALTH INSURANCE AGENCY AND. 2017;(c).

14. Pham P, Vinck P, Kreutzer T, Milner J, Dorey A, Musaraj P, et al. KoBoToolbox | Data Collection Tools for Challenging Environments [Internet]. Kobo Toolbox. 2019. Available from: https://www.kobotoolbox.org/

15. Onoka CA, Onwujekwe OE, Hanson K UB. Examining catastrophic health expenditures at variable thresholds using household consumption expenditure diaries. Trop Med Int Heal. 2011;16(10):13341341.

16. Modern Ghana. Launch of National Health Insurance postponed [Internet]. 2004 [cited 2019 Nov 25]. p. 2004. Available from: https://www.modernghana.com/news/47584/launch-of-national-healthinsurance-postponed.html

17. Attah FM, Anam BE, Juliet NC. Thrift Credit Services and Socio Economic Wellbeing of Community Dwellers in Cross River State 1. 2017;7(2):146-65.

18. Adisa 0 . Investigating determinants of catastrophic health spending among poorly insured elderly households in urban Nigeria. Int J Equity Health [Internet]. 2015;14(1):1-11. Available from: http://dx.doi.org/10.1186/s12939-015-0188-5

19. Janssens W, Goedecke J, Bree GJD, Aderibigbe SA, Akande TM, Mesnard A. The financial burden of non-communicable chronic diseases in rural Nigeria: Wealth and gender heterogeneity in health care utilization and health expenditures. PLoS One [Internet]. 2016;11(11):1-19. Available from: http://dx.doi.org/10.1371/journal.pone.0166121 
20. Olawoye JE, Omololu FO, Aderinto Y, Adeyefa I, Adeyemo D, Osotimehin B. Social construction of manhood in Nigeria: Implications for male responsibility in reproductive health. Etude la Popul Africaine. 2004;19(2):1-20.

21. NPC. Nigeria. 2013;

22. Aregbeshola BS KS. Determinants of catastrophic health expenditure in Nigeria. Eur J Heal Econ. 2017;1-12.

23. Qatar Pharmaceutical \& Healthcare. Suspension Of National Health Insurance Creates An Uncertain Future [Internet]. BMI Research. 2016 [cited 2017 Jun 5]. Available from:

http://www.bmiresearch.com/articles/suspension-of-national-health-insurance-creates-an-uncertainfuture

24. Okoroh J, Essoun S, Seddoh A, Harris H, Weissman JS, Dsane-Selby L, et al. Evaluating the impact of the national health insurance scheme of Ghana on out of pocket expenditures: A systematic review. BMC Health Serv Res. 2018;18(1).

25. Chemouni B. The political path to universal health coverage: Power, ideas and community-based health insurance in Rwanda. World Dev. 2018;106:87-98.

26. Lee B, Tarimo K, Dutta A. Tanzania's Improved Community Health Fund An Analysis of Scale-Up Plans and Design. HP Policy Br [Internet]. 2018;(October). Available from: http://www.healthpolicyplus.com/ns/pubs/10259-10469_TanzaniaiCHFScaleUpbrief.pdf

\section{Figures}

\begin{tabular}{|c|c|c|c|c|c|c|c|c|c|c|c|c|c|c|c|c|}
\hline & 2015 & & & & 2016 & & & & 2017 & & & & 2018 & & & \\
\hline & Q1 & Q2 & Q3 & Q4 & Q1 & Q2 & Q3 & QA & Q1 & Q2 & Q3 & Q4 & Q1 & Q2 & Q3 & Q4 \\
\hline KCHIP & \multicolumn{16}{|c|}{ 137,714 phasing out } \\
\hline KSHIP & signed law & & & & & & & & & & & & & & & start roll out? \\
\hline Study & & & & & & & & & & & & spectiv & analyses & & veys & \\
\hline
\end{tabular}

\section{Figure 1}

Major policy milestone, study period and clients' enrolment trend in Kwara Community health insurance scheme between 2015 and 2018. 


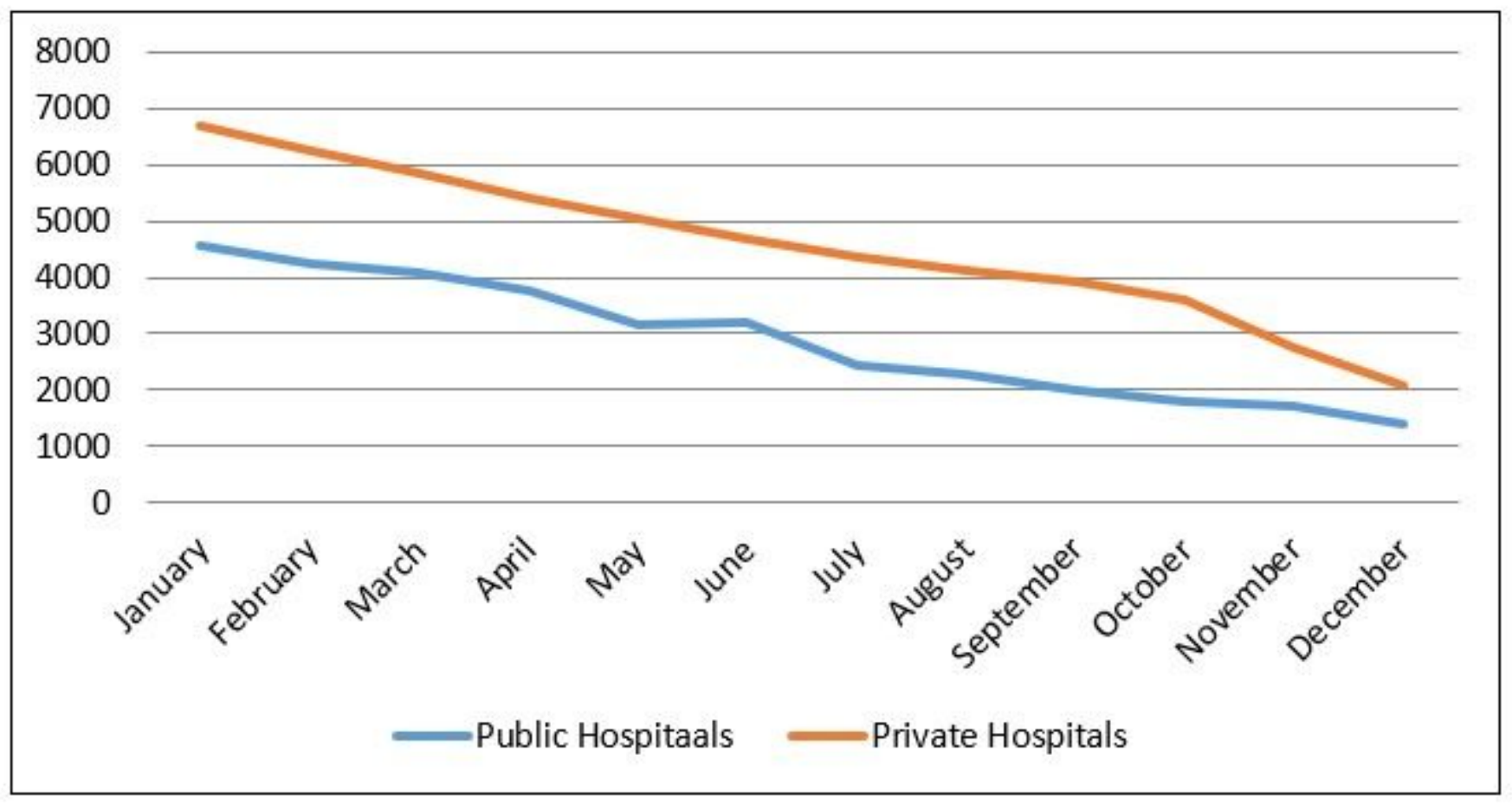

Figure 2

Out-patients' visits by month for the year 2016 across the public and private health facilities

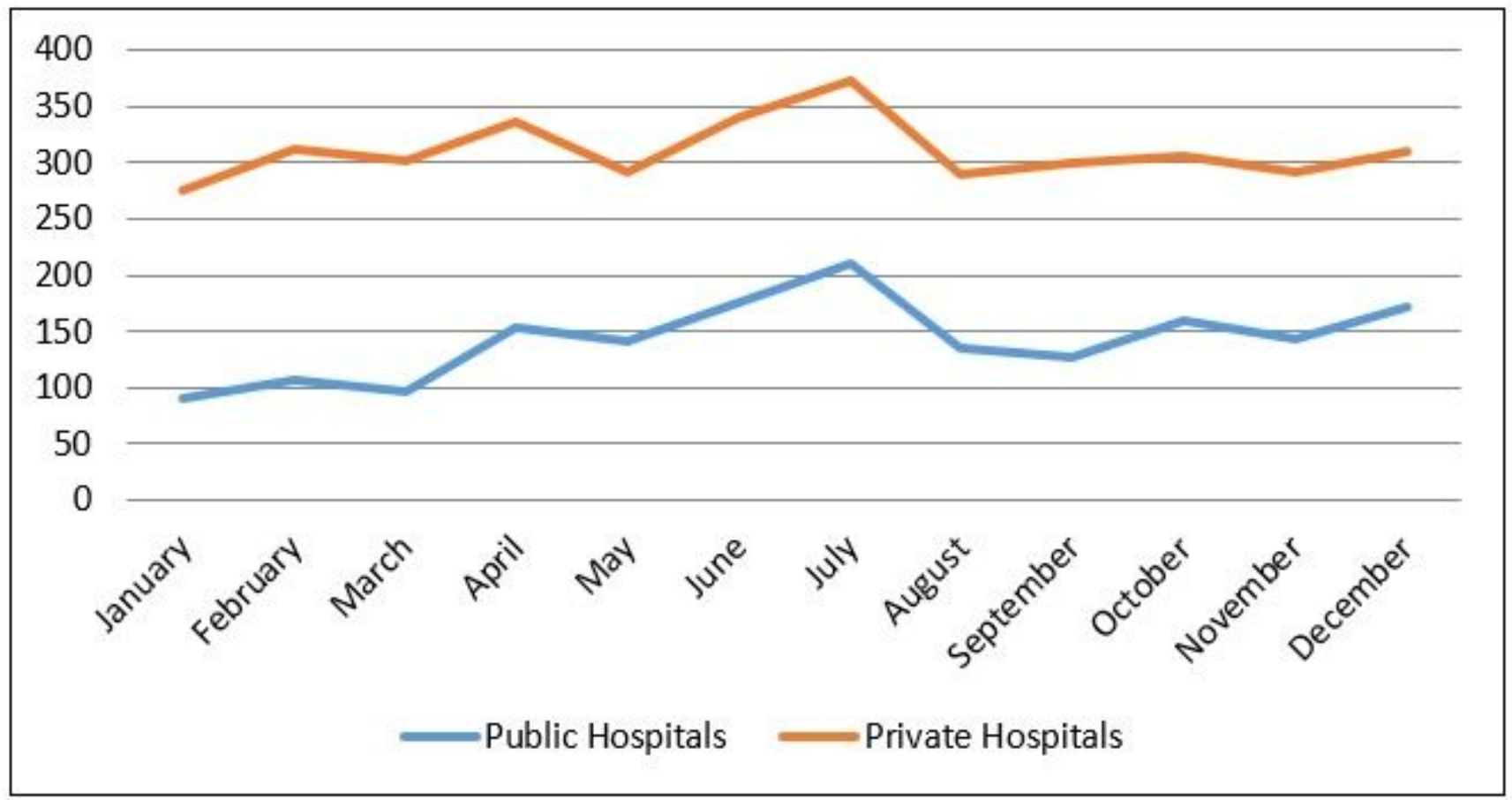


Figure 3

In-patient visits by month for the year 2016 across public and private health facilities. 